\title{
The Tensions Between Student Dropout and Flexibility in Learning Design: The Voices of Professors in Open Online Higher Education
}

Marlon Xavier and Julio Meneses

Faculty of Psychology and Education Sciences, Universitat Oberta de Catalunya (UOC), Barcelona, Spain

\begin{abstract}
Flexibility is typical of open universities and their e-learning designs. While this constitutes their main attraction, promising learners will be able to study "anytime, anyplace," this also demands more selfregulation and engagement, a cause for student dropout. This case study explores professors' experiences of flexibility in e-learning design and continuous assessment and their perception of the risks and opportunities that more flexibility implies for student persistence and dropout. In-depth interviews with 18 full professors, who are the e-learning designers of undergraduate courses at the Open University of Catalonia (UOC), were analyzed, employing qualitative content analysis. According to the professors, the main causes for dropout are student-centered, yet they are connected to learning design: workload and time availability, as well as students' expectations, profiles, and time management skills. In the professors' view, flexibility has both positive and negative effects. Some are conducive to engagement and persistence: improvement of personalized feedback, formative assessment, and module workload. Others generate resistance: more flexibility may increase workload, procrastination, dropout, and risk of losing professorial control, and may threaten educational standards and quality. Untangling the tensions between dropout and flexibility may enhance learning design and educational practices that help prevent student dropout. Stakeholders should focus on measures perceived as positive, such as assessment extension, personalized feedback and monitoring, and course workload calibration. As higher education is globally turning to online delivery due to the COVID-19 viral pandemic, such findings may be useful in both hybrid and fully online educational contexts.
\end{abstract}

Keywords: online higher education, learning design, continuous assessment, flexible learning, persistence, dropout 


\section{Introduction}

Learning design (LD) can be defined as "the practice of devising effective learning experiences aimed at achieving defined educational objectives in a given context” (Mor et al., 2015, p. 221), impacting many aspects of the students' experience. Course design and learning environment are key factors in dropout and persistence (Lee \& Choi, 2011). As central elements of LD, assessment and feedback are key drivers for e-learning (Armellini \& Aiyegbayo, 2009). Assessment is probably the principal contact between student and teacher; feedback on assignments is often the main vehicle for teaching (Simpson, 2003). Continuous assessment (CA), through continuous feedback, can thus be used to improve student learning, achievement, and persistence (Nguyen et al., 2017).

Dropout represents one of the greatest challenges faced by online educators and administrators, as online higher education (OHE) courses have significantly higher student dropout rates than conventional courses (Lee \& Choi, 2011). However, the problem of dropout has become exceedingly important for both OHE and higher education (HE) stakeholders, as we face the online turn-the growing trend in HE towards transitioning to online teaching (Han et al., 2019), which has recently been exacerbated by the impact of COVID-19, forcing HE institutions to adopt online delivery overnight (Naylor \& Nyanjom, 2020).

Dropout can be broadly defined as withdrawal and non-completion of a course or program (Xavier \& Meneses, 2020). However, for our purposes in this study, dropout refers to withdrawal from a course's CA process. Persistence is synonymous with success and the opposite of dropout: a multifaceted phenomenon defined as completing a course and continuing to program completion (Hart, 2012). Student engagement is associated with success and persistence; it is contingent on both an institution's structures, policies, actors, and practices, and how students avail themselves to opportunities for engagement (Dexter, 2015). Thus, dropout, persistence, and engagement depend on the learners, the institution (LD and faculty), and external factors (time pressures and life circumstances such as family, health, work, and financial issues). In this study, we focus primarily on the roles of LD and flexibility.

Flexibility is considered the most crucial element of part-time distance learning. Flexible learning addresses the differences in needs, preferences, and skills between students by providing them different choices regarding what, where, when, why, and how to learn, supporting personalized learning and a student-centered approach (Soffer et al., 2019). Flexibility has become the main attraction of OHE, especially for busy, time-poor nontraditional students (Butcher \& Rose-Adams, 2015). Open OHE promises learners they will be able to study when, how, and what they want-“anytime, anyplace," a claim that has been criticized (Houlden \& Veletsianos, 2019). However, flexibility is also a cause for student dropout, for it demands more self-regulation, self-motivation, and time management skills and can lead to procrastination. Hence, debate is ongoing on whether to provide more or less flexibility in OHE and the impact it may have upon students' success.

Some authors (Deschacht \& Goeman, 2015; Simpson, 2003) defend flexibilization of course design, structure, and workload to accommodate students' employment challenges (Moore \& Greenland, 2017), including assessment policies, points, deadlines, and strategies: "Inflexible barriers resulting from time pressures (especially at assessment points) can increase the stress of juggling competing priorities" (Butcher \& Rose-Adams, 2015, p. 133). However, more flexibility and less guidelines may increase the risk of procrastination and place more demands on student self-regulation and motivation. Thus, other authors have found flexibility to be a variable that predicts student dropout (Michinov et al., 2011). 
Additionally, offering more flexibility to the learner also places higher demands on instructors, often requiring more time and effort from them (Nikolova \& Collis, 1998), while also diminishing predictability and conditions for planning. However, literature on the critical experiences of professors as learning designers on this matter is scant.

\section{Context of Research}

Our research was done in the context of a fully online open university, the Open University of Catalonia (UOC), which employs a flexible, student-centered e-learning model and an asynchronous mode (Sangrà, 2002). UOC's typical students are nontraditional learners: adults with jobs and family responsibilities; $83 \%$ are 30 years of age or over, and 90\% both study and work (Sánchez-Gelabert et al., 2020). Someone with such a profile is more likely to suffer from conflictive commitments, which negatively impact academic performance, thus influencing dropout proneness (Owen et al., 2017). The dropout rate at UOC is $57.6 \%$ in a long-term program perspective, with first semester dropouts accounting for nearly half of this total (Grau-Valldosera et al., 2018).

UOC's LD is characterized by the full integration of CA, of a diagnostic, formative, and summative character, employing graded continuous assessment activities (CAAs), which students submit online according to a preestablished calendar. $\mathrm{CA}$ is devised as a mechanism for learning and providing feedback in the learning process. To pass a course, students have to succeed in the CA process; in some cases, they are given the alternative of only sitting final (face-to-face) summative exams, which are mandatory in undergraduate programs and for which the CA process prepares them. Therefore, dropping out of the CA process does not necessarily imply that the student dropped out of the course or failed it; but it is very often the first and most important step towards attrition. Nonetheless, at UOC, dropout from CA is almost synonymous with dropout from or failing a course. Thus, CA is arguably the prime moment to intervene in terms of dropout-for professors and instructors cannot control intersemester dropout. Thus, UOC's LD is very structured and competence-oriented yet not very flexible in key aspects: the calendar is usually strict, with definite deadlines for CAAs and exams, and there are no official policies for assignment extensions or for the possibility of making up for a missed or failed CAA. Full professors (FPs) are responsible for the e-learning design of courses, including assessment and educational resources and goals, and for supervising the work of instructors. Instructors (part-time adjunct professors) are mainly responsible for teaching courses. Academic advisors support students in everything not related to the course itself-in enrollment, in problem solution in general, and as intermediaries in the communication with other faculty and the institution.

This study was developed in the context of an intervention at the UOC, designed to increase engagement and persistence in the CA process: a seminar of a reflective and formative character, with FPs (learning designers) and experts sharing best practices regarding successful incorporation of flexibility measures in courses, according to their experiences. FPs were invited to apply one or more forms of flexibility in their courses, according to their own diagnostics and their course's specific assessment model, type of activities, and learning objectives. Among the different suggested measures intended to make LD and CA more flexible were offers of progressive CA; personalized feedback and monitoring; more diversified learning resources; the possibility of making up for a low mark in a CAA in subsequent CAAs; the creation of a "CAAo" (ungraded mark) to induce a smoother entry in the course, and as a diagnosis tool; and acceptance of assignment extension requests. Grounded in the assumption that LD should be an 
iterative and collaborative process (Bennett et al., 2009), such formative action was a first step for the subsequent voluntary incorporation of flexibility measures in the FPs' LD of courses. However, in this study, we do not assess their efficacy.

As Veletsianos and Houlden (2019) stress, flexibility requires further inquiry-how can aspects of open OHE be made more flexible? Which elements may benefit students the most, preventing dropout and fostering engagement and success? Our main focus here is on LD, for, from the professors' perspective, it is during the course that they can intervene-especially on the CA process and the feedback it may provide. However, there is a dearth of inquiry on the lived experiences of professors (Badia \& Chumpitaz-Campos, 2018), especially employing qualitative approaches to investigate the relations between LD and student persistence. Thus, generating knowledge about professors' experiences and perceptions of flexibility in OHE settings may aid OHE institutions to address dropout, retention, and persistence issues, concentrating on early detection and on providing and evaluating the support and interventions needed.

To address such a gap, this research's aim was to examine the nature of the professors' experience of and views about flexibility in e-LD and CA; their perceptions of the main student dropout factors; and the risks and opportunities that more flexibility would imply for persistence, attrition, and engagement.

\section{Method}

\section{Design and Participants}

This case study employed an exploratory, cross-sectional, qualitative design. The "bounded entity" (Putney, 2010, p. 115) we inquired into was the UOC, and its primary unit of analysis (Yin, 2002) consisted of the experiences of UOC professors. A purposive, criterion-based sampling method was employed, using a maximum variation sampling approach (Ritchie et al., 2014). Participants included $18 \mathrm{FPs}-50 \%$ female, ages ranging from 35 to 59 years $(M=46.22, S D=6.59)$, with experience as learning designers in OHE ranging from 1 to 13 years $(M=9.06, S D=4.58)$-from the UOC who had participated in the formative seminar. The research team sent an e-mail to all participants, inviting them to take part in the study. Professors were randomly selected according to gender and the rates of persistence (lower, average, and higher) in their courses' CAs in relation to the rates in their respective programs. Thus, three professors per department-each responsible for a different undergraduate course-were selected. Each participant was assigned a code to ensure anonymity (see Table 1). All courses were mandatory, apart from the optional one coordinated by the P2 professor. Courses coordinated by professors $\mathrm{P} 4, \mathrm{P} 7, \mathrm{P} 9, \mathrm{P} 12$, $\mathrm{P} 16$, and $\mathrm{P} 18$ were introductory (first-year) courses. In terms of limitations, our sample is random but relatively small-that is, it was not intended to be statistically representative. Instead, according to the maximum variation sampling approach, we sought to collect a diversity of professors' experiences in relation to different study programs, courses, and levels of CA persistence. 


\section{Table 1}

Distribution of Participants According to Selection Criteria

\begin{tabular}{l|c|c|c}
\hline \hline Department & $\begin{array}{c}\text { Lower persistence } \\
\text { course }\end{array}$ & $\begin{array}{c}\text { Average persistence } \\
\text { course }\end{array}$ & $\begin{array}{c}\text { Higher } \\
\text { persistence course }\end{array}$ \\
\hline Arts and Humanities & P14, male & $\mathrm{P}_{15}$, male & P9, female \\
\hline Business and Economics & P8, female & P13, male & P16, female \\
\hline $\begin{array}{l}\text { Computer Science, Multimedia, } \\
\text { and Telecommunication }\end{array}$ & P1, male & P17, male & P5, male \\
\hline $\begin{array}{l}\text { Information and Communication } \\
\text { Sciences }\end{array}$ & P18, male & P4, female & P6, male \\
\hline Law and Political Science & P10, female & $\mathrm{P}_{12,}$ female & P11, female \\
\hline Psychology and Education & P7, female & $\mathrm{P}_{3}$, male & P2, female \\
\hline \hline
\end{tabular}

\section{Data Collection}

During in-depth, face-to-face, hour-long semi-structured interviews, the professors were presented with different flexibility measures and asked to reflect upon their convenience and, particularly, how increasing flexibility may impact persistence and dropout in their courses. Interview protocols were developed according to the themes under study, the phenomena and factors that are relevant to them, the specificities of the actors studied, and UOC's LD. Interview questions focused on the following topics: dropout factors; characteristics of the course, its CA process, and program; and how the professors perceived different measures in relation to student dropout and the specific course they designed and coordinated. All participants gave informed consent. The study-including data collection, handling, and protection-complied with the university's ethical requirements. Interview protocols are available upon request.

\section{Data Analysis}

The interviews (in Catalan or Spanish) were transcribed verbatim and analyzed iteratively and manually following Schreier's (2016) established qualitative content analysis, by searching for selected aspects of meaning that were relevant to the research aims. Through double coding (first a trial coding, performed by the first author, and then a final coding, revising and expanding the frame), main themes and codes were generated and agreed upon by both authors. For reasons of clarity, in the next section, we present the results, structuring them in terms of the research aims, and not in terms of themes and codes (which are stressed in italics).

\section{Results}

This section employs illustrative vignettes to summarize our results and discusses them in contrast with the literature. In the professors' voices, some variables were much more important for dropout; flexibility had different meanings, presenting both positive and negative effects, and its viability was discussed; and some intervention measures were perceived as more necessary and positive. Longer or 
shorter experience as OHE learning designers did not seem to significatively affect the professors' perceptions.

\section{Perception of Dropout Factors}

In the professors' experience, the main causes for dropout (of CA) in their courses were mainly studentcentered-learner factors-yet some are connected to e-LD. One of the main factors mentioned was time management skills: the professors perceived that many students who dropped out of their courses were time poor and/or had poor time management:

It's mainly time-related problems, time management issues. It might be due to professional problems, or family, domestic, job issues ... which do not allow students to continue. [Or else] they've enrolled in too many courses and maybe are first- or second-semester students and enrolled in six [courses], then they get overwhelmed and have to prioritize. ... It's clearly about lack of planification. (P6).

In this sense, life circumstances often play a crucial role: dropouts usually "have some work-related problem, normally it's either work or family [issues]" (P11). Juggling study load with work and family commitments is a major problem for first-year, nontraditional students (Kara et al., 2019). Procrastination was also seen as a common issue: "It might be that the students are used to engaging with the CAA only in the last week. It seems the student [dropout] is not capable of self-regulation" ( $\left.\mathrm{P}_{4}\right)$. However, the literature highlights that self-regulation skills may be less important when the student has little available time (Veletsianos et al., 2021). For the professors, time-related issues were the most reported reason for withdrawal. According to Ashby (2004), the most important dropout variable in OHE is difficulties in juggling studies, work, and life demands; academic procrastination and time management issues often make such difficulties seem unsurmountable (Michinov et al., 2011). However, blaming the students may be a form of external attribution by the FPs and a means to avoid responsibility for the roles LD and themselves play in dropout. In this case, FPs were possibly adopting Darwinista (students drop out because they are somehow unfit) and Fatalista (they drop out due to reasons beyond their control) attitudes to student retention (Simpson, 2013).

Connected to this, student profiles also matter. First-year students "who enroll late, students who haven't grasped well the [online] campus system or how it works ... they are a bit lost and ... they are the profile who misses the first CAAs [and drops out]" (P12). Indeed, new students are particularly prone to dropping out (Grau-Valldosera et al., 2018). Participants also mentioned students' abilities and skills regarding OHE and technology, as well as many other intrinsic factors related to self-motivation and engagement, such as previous professional and OHE experience. In this regard, their comments coincided with the literature: individual student success (and dropout) is influenced by the educational environment, including LD and CA, and student characteristics in general, which include digital literacy and previous OHE experience (Day et al., 2018).

The gap between student misconceptions and expectations and actual experience also contribute to dropout, especially among first-year students:

Learners begin their degrees and, of course, run into reality. It's a university, not an e-learning that is that cool or that easy or that simple. $(\mathrm{P} 7)$ 
They are not well-informed. This is a university degree and requires effort. They see it as something super easy. (P8)

They were too optimistic regarding what they could undertake. (P15)

It seems new-entry learners often take broad university messages that they can study when, how, and what they want, and that online learning is "easier" due to such flexibility (Hyllegard et al., 2008). This may generate misconceptions and inaccurate expectations (Bawa, 2016), such as underestimation of time demands and workload (Korstange et al., 2020), which later impact students' motivation, performance, and time availability. Accurate expectations facilitate student satisfaction and motivation, especially during the critical first year of studies (Henry, 2018).

Finally, FPs voiced their concern about the timing of student withdrawal from CA (early dropout): most students drop out after the first CAA, not submitting it or else not passing it, and consequently not able to follow their courses. Others drop out after the second CAA, but this occurs less often. This knowledge is important for the prioritization and efficacy of early interventions and appears to happen in other open universities: "Much dropout occurs very heavily in the first few weeks of a first module" (Woodley \& Simpson, 2014, p. 461).

\section{Learning Design and Dropout}

Although FPs mostly associated dropout with student factors, they also expressed that many general characteristics of their courses' LD were connected to higher rates of dropout. Course and CA workload were often mentioned:

The problem is the [course] workload. (P2)

Too many CAAs and they require too much work. (P9)

Learners who don't get engaged with the first CAA. The learning resources are very extensive. $\left(\mathrm{P}_{3}\right)$

In general, the more difficult or complex the $\mathrm{CA}$ is, the lower the engagement and performance will be in the CA. Courses with high complexity ( $\left.\mathrm{P}_{5}, \mathrm{P} 8, \mathrm{P} 10\right)$ or extensive course content, as well as particularly difficult courses $\left(\mathrm{P}_{5}, \mathrm{P}_{10}\right)$ and those that are too theoretical $\left(\mathrm{P}_{7}\right)$, tended to have high dropout rates. Some FPs ( $\left.\mathrm{P}_{1}, \mathrm{P}_{5}\right)$ mentioned that their courses must be complex and difficult, for they are supposed to provide students with core knowledge and skills. However, the literature stresses that too difficult assignments and demanding courses or programs (Kara et al., 2019) are important challenges to completion. Students' sense of overload may be caused by inadequate LD, impacting their time availability and constraints: "They try to do too many things in too little time" (P4). Time constraints or lack of time-here as consequences of LD-make up one of the main dropout factors in the literature.

Introductory courses (type of course) were also problematic, as their attendance is mostly composed of first-year students, who are much more prone to dropping out. Moreover, such courses tend to have very large class sizes, which makes it more difficult for faculty to be flexible in assessment deadlines and provide personalized feedback and support: "We grant [assessment extension requests] only exceptionally. Now, do I think it'd work? No. I don't think that's the problem. What happens is that it is titanic ... these classes have 70 students” $\left(\mathrm{P}_{7}\right)$. 
LD also involves the design of the interactions between the different actors in OHE, including student support. However, our participants only mentioned such factors peripherally, focusing instead on the roles and attitudes of the different actors. For instance, instructors, who are responsible for putting LD into practice, were deemed relevant for dropout and persistence:

The other factor is ... the instructor's teaching practices and presence. ( $\left.\mathrm{P}_{5}\right)$

There are instructors who are more empathetic, placing themselves much more in the student's shoes and do many more actions, while others do the bare minimum. The instructor is a basic element. (P12)

Instructor support and connection play a critical role in student retention (Stone \& O’Shea, 2019).

Academic advisors were also perceived to play an important role, especially for first-year students: "They can help the ones who are beginning, no? I believe the academic advisor is a key figure when you have a new student. They should know how to help that student pass the CA" (P12). Orientation programs have been shown to increase retention through early elucidation of student expectations and clear advising (Henry, 2018).

\section{Flexible Measures in Learning Design: Risks and Opportunities}

For FPs, flexibility can have both positive and negative effects in terms of possible benefits and costs/risks. Such perceptions depend mainly on the specific characteristics of the course and students: FPs appraised flexibility measures confronting such characteristics and the expectations for the course they were responsible for.

Some flexibility measures were seen as conducive to engagement and persistence (engagement measures). Improving personalized feedback, especially for new students and those students who fail the first CAA, was deemed crucial:

I believe that every accrual in personalized feedback and monitoring can end up resulting in improved learning. ( $\mathrm{P} 1)$

An exhaustive monitoring of these students [is needed], so as to prevent dropout-there's little we can do, but we make the effort. (P12)

The student is very thankful for that. However, it's a lot of work [for faculty]. (P8)

Reducing module content/workload (P2)-that is, simplifying learning resources-was also seen as beneficial: "Sometimes the more resources you give them [students], the more you overwhelm them" (P11). However, sometimes this was seen as ineffectual: "Semester after semester, we've been reducing the course workload, but it's still problematic" ( $\mathrm{P}_{5}$ ). Indeed, according to the literature, high-quality personalized feedback is the most powerful influence on student achievement (Mulliner \& Tucker, 2017), and diminishing course workload and difficulty may be beneficial for completion (Willging \& Johnson, 2009).

Changing LD in terms of the flexibility of CA practices was also seen as important, especially the assessment practices that affect the first assignment (e.g., adopting a diagnostic or lighter first CAA): "I've done it in my program, it's very good and we've already planned to offer it in the next semester.... 
It's fantastic ... it helps the students to orient themselves better" (P9). Offering reparatory CAAs was deemed beneficial: "Yes, it's good. Everything that helps saving the student is fine" (P18). However, few FPs perceived making deadlines flexible as positive:

Yes, yes, it can foster more motivation. (P13)

It may create a certain chaos, but it can also lead to an absolute personalization. (P18)

Flexible deadlines and assessments seem to be important in the literature, for compulsory (and at times overlapping) assignment deadlines and overly defined pace of learning reduce students' control over their time, placing greater demands on their time management and availability (Henry, 2018). In an inflexible LD with strict deadlines, few CAAs, and no alternatives for failing or not submitting the first assignment, students are faced with only three choices: to persist, so as to benefit from CA feedback and learning; to withdraw; or to sit final exams: "The first CAA ... is like the touchstone. If you pass it, you keep going, if you don't, you drop out" ( $\left.\mathrm{P}_{5}\right)$. In this situation, the first assignment functions as an early exam; if the student fails it and withdraws from the CA process, they will not benefit from assessment feedback-which substantially reduces their possibility of passing the course. Besides, retention is strongly informed by student performance (Henry, 2018).

However, overall, such flexibility measures generated strong resistance, due to perceived risks. Flexibilizing deadlines "is a problem, then you are faced with very complicated dynamics ... in that you don't have control over such specific issue" ( $\left.\mathrm{P}_{3}\right)$. It "creates a disadvantage for the students who follow the calendar ... in the end, you have to maintain certain criteria. It's detrimental to [education] quality" (P12). For many FPs, more flexibility may increase student workload, procrastination, dropout, andfor faculty-the risk of losing professorial control: "Flexibilizing means giving more time? Then we have screwed it up. If you give more time everyone seizes this second option ... If there's a limit, there's a limit” (P3). More flexibility was often seen as a threat to educational standards and quality-demanding less of students and relaxing deadlines and course difficulty, for instance, would eventually produce poorer learning outcomes:

I've lowered the course's academic level. I don't want to relax it more. $\left(\mathrm{P}_{7}\right)$

To lower the standards ... so as to not lose students ... that is, the mixing of business with education, it's complicated. (P15)

In a sense, many FPs seemed to perceive more flexibility as a weakness. The impression was that many had accepted some flexibility but did not want to "give away" more of it because it went against their principles. For Veletsianos and Houlden (2019), such perception is a commonly perceived trade-off required by flexible learning: flexibility might necessarily come at the cost of rigor or other standards. However, professorial resistance may also be connected to traditional arguments from faculty for not changing their practices to be more learner-centered, which involves a shift of power from faculty to learners (Weimer, 2013). This appears to be a central conundrum for FPs: if retention and dropout are institutional problems, and FPs think they are important, then how can persistence and engagement be fostered? And how can it be done without endangering what we professors expect students to do (and often they don't)?

Many FPs defended more flexibility but said it demands more time and effort from faculty (costs): 
I'm a great advocate of flexibility, but then it has some consequences ... for myself, as a FP, and for my team of instructors. At any rate, it implies [more] time and dedication. (P17)

The idea may be good, but it requires a lot of time [from faculty] so as to put it into practice to make it work. $\left(\mathrm{P}_{5}\right)$

What we have to do is to make it viable. (P18)

Class sizes (often with 70 students) hinder instructors' adoption of flexible measures such as personalized feedback in the course's first weeks, as it would be too time-consuming (P8; P13). Brigham (1992) alludes to a need for "faculty flexibility" so as to develop successfully flexible online courses (p. 186). However, the literature stresses that flexibility can be a challenge for instructors, implying more workload and time, thus generating resistance (Veletsianos \& Houlden, 2019). According to McNaught (2013), "the massive impost of workload on staff within the sector has been a significant issue in the reluctance for staff to engage" with (more) flexible learning (p. 869).

\section{Revisiting the Problem with First-Year Students}

The theme of first-year students emerged as a central preoccupation for FPs-including the ones who do not design and oversee introductory courses, for thanks to open enrollment pathways, a mix of firstyear, sophomore, and senior students may be present in any given course. Many FPs fear that first-year students are especially prone to dropping out for many reasons: lack of self-regulation skills, less academic preparedness, lack of familiarity with the online education model, time poverty, and so on. Adapting to the CA process is thus likely to be more difficult for them. First-year transition is most critical in shaping persistence decisions (Trotter \& Roberts, 2006), but it can be especially challenging for online students (Henry, 2018).

In this sense, the traditionally flexible entry requirements of open universities represent an additional and major problem. Most FPs pointed out that open access is likely to produce high rates of dropoutwhich they attempt to remedy by implementing some flexibility measures, especially in introductory courses, while remaining resistant to other measures. In other words, they saw a tension between entry flexibility in the programs and then having to flexibilize electronic LD in their courses. Thus, some FPs implicitly defended less flexibility for entry (i.e., raising program admission requirements): "If there were an initial filter ... then you can think about where you want the university to go ... you could think about it differently" $\left(\mathrm{P}_{7}\right)$. One FP mentioned that

when you try to diminish dropout, you end up lowering [educational standards]. It's too easy to fall in that trap. Maybe there are too many people in university [degrees] ... there are too many students who simply don't qualify, and nothing happens. (P16)

Indeed, many of these perceptions seem to be connected to a fundamental tension between open and university-open universities want and promise to be open and flexible while striving to avoid the possible consequences (poorer quality and higher dropout rates) in comparison with the traditional, on-campus university model. However, most FPs do not explicitly advocate restrictions to open admission but rather emphasize the effective management of misconceptions and inappropriate expectations, especially through early academic advising. This is in agreement with the literature: "Make it harder to get in. Not through selection but with brutal honesty about what the students will be getting into ... . Make it harder to get out" (Woodley \& Simpson, 2014, p. 468). Especially in the case of 
open universities, which offer flexible open access policies but also stringently demand motivation, selfregulation, and time availability, 'expectation management' is the predominant aim, rather than selection” (Delnoij et al., 2020, p. 15).

\section{Conclusion}

This article has analyzed the reflections and perceptions among professors on flexibility measures addressing dropout and persistence, born out of sharing common practices and experiences. Based on an agnostic approach regarding flexibility, FPs were invited to experiment and imagine different flexible measures in the specific context of their courses. Confronting the problem and the possible flexibility actions generated difficulties and tensions regarding accommodating students' needs, changing institutional practices, and fostering student retention, all while preserving standards and education models. In this regard, many specific advantages regarding possible measures were voiced, especially regarding $\mathrm{LD}, \mathrm{CA}$, and personalized feedback and support.

However, flexibility was also seen as risky and problematic, given that FPs worried about increasing demands on faculty and perceived a general lack of organization and planning among many students in their courses, which may lead to dropout and failure if more flexibility is offered. In sum, flexibility cannot be viewed as an either-or situation; its adequacy depends on the context (educational model, course, and students) and also on the experiences and viewpoints of professors and learning designers.

In this sense, the widespread claim of "anytime, anyplace" (and "for everyone") possibilities offered by flexible OHE must be seen through a critical lens (Veletsianos \& Houlden, 2019). Students who enter OHE are often unprepared for the huge demands on their self-regulation and time management, and many have unreal expectations; besides, their pace of study is often constricted by strict calendars. For them, while "flexibility can be seen as a virtue, enabling multitasking and fluidity of roles, it can also be seen as a curse, impacting negatively on family life and creating new stress" (Kahu et al., 2014, p. 524). Online studies tend to blur the boundaries between study and home or work, often occasioning conflict between the three spheres, which frequently leads to time poverty and course dropout. Flexible, open entry frequently feeds such a conundrum, as it allows access to unprepared students.

Therefore, flexibility in OHE has both positive and negative consequences. This is a problem, for OHE has become traditionally flexible, especially in open universities, where flexibility is seen as a value principle, an ethos essential for inclusion and accessibility (Naidu, 2017). This paper has looked at one open university as a case study, so direct generalization might be difficult. Nonetheless, some of our results might be valid for other open OHE models with asynchronous learning formats based on CA. However, the key issues studied here-the perceptions of professors who are learning designers about flexibility, dropout factors, LD, assessment models, conceptions, and standards of OHE-may be comparable to those observed in other OHE and hybrid HE institutions. Detecting and analyzing such issues can represent an opportunity to review flexibility policies and LD choices. Thus, we recommend further research on the lived experiences of faculty regarding such problems, perhaps comparing the resistances and risks perceived to the ones traditionally connected to the learner-centered learning paradigm and to the tensions between open and (traditional) university models.

This is especially important given what we have termed the contemporary online turn: the trend of HE increasingly turning to online delivery and its recent intensification by the global pandemic. Even 
though this research was performed prior to the emergence of COVID-19, findings suggest that untangling the relations between online flexibility, $\mathrm{LD}$, and dropout is crucial to prevent attrition in both hybrid and online HE, as well as to ensure that the now much-needed flexibility of OHE is employed with positive results in terms of optimizing retention and success. As most campus-based HE is presently turning to online formats, the results of this debate should be of interest to all educators who now face the inherent problems of the online turn. In this sense, this discussion goes beyond the flexibility measures presented here, which are context dependent. The tensions and opportunities they may generate should therefore be studied in different learning contexts (open, online, hybrid) and HE institutions.

In conclusion, too much flexibility was seen by FPs as disorganizing and lacking rigor, lowering the standards of education. It seems that the ideal is balance between structure and flexibility. Providing a structured yet flexible classroom environment was seen by students as a key element for effective online teaching (Young, 2006); strict scheduling helps keep some students on track, but too much flexibility poses organizational challenges (Henry, 2018). Professors voiced such fundamental tension:

[Faculty] are very flexible. Flexible enough, to a certain extent, because you also have to be fair with the students who follow the calendar, no? ... In this confrontation of positive values, that is, to be flexible but also disciplined, well, we need to find a balance. (P14)

\section{Declaration of Interest}

No potential conflict of interest was reported by the authors.

\section{Acknowledgments}

This research was supported by a doctoral grant from the Universitat Oberta de Catalunya. We also thank Dr. Antoni Badia for his collaboration in designing interview protocols; Roger Griset, who conducted the interviews; and Marina Serra for transcribing them. 


\section{References}

Armellini, A., \& Aiyegbayo, O. (2009). Learning design and assessment with e-tivities. British Journal of Educational Technology, 41(6), 922-935. https://doi.org/10.1111/j.1467853.5.2009.01013.x

Ashby, A. (2004). Monitoring student retention in the Open University: definition, measurement, interpretation and action. Open Learning, 19(1), 65-77. https://doi.org/10.1080/0268051042000177854

Badia, A., \& Chumpitaz-Campos, L. (2018). Teachers learn about student learning assessment through a teacher education process. Studies in Educational Evaluation, 58, 1-7. https://doi.org/10.1016/j.stueduc.2018.05.004

Bawa, P. (2016). Retention in online courses: Exploring issues and solutions-A literature review. Sage Open, 6(1). https://doi.org/10.1177/2158244015621777

Bennett, S., Agostinho, S., Lockyer, L., \& Harper, B. (2009). Researching learning design in open, distance, and flexible learning: Investigating approaches to supporting design processes and practices. Distance Education, 30, 175-177. https://doi.org/10.1080/01587910903023173

Brigham, D. E. (1992). Factors affecting the development of distance education courses. Distance Education, 13, 169-192. https://doi.org/10.1080/0158791920130203

Butcher, J., \& Rose-Adams, J. (2015). Part-time learners in open and distance learning: Revisiting the critical importance of choice, flexibility and employability. Open Learning, 3O(2), 127-137. https://doi.org/10.1080/02680513.2015.1055719

Day, I. N. Z., van Blankenstein, F. M., Westenberg, P. M., \& Admiraal, W. F. (2018). Explaining individual student success using continuous assessment types and student characteristics. Higher Education Research \& Development, 37(5), 937-951. https://doi.org/10.1080/07294360.2018.1466868

Delnoij, L., Dirkx, K., Janssen, J., \& Martens, R. L. (2020). Predicting and resolving non-completion in higher (online) education-A literature review. Educational Research Review, 29, Article 100313. https://doi.org/10.1016/j.edurev.2020.100313

Deschacht, N., \& Goeman, K. (2015). The effect of blended learning on course persistence and performance of adult learners: A difference-in-differences analysis. Computers \& Education, 87, 83-89. https://doi.org/10.1016/j.compedu.2015.03.020

Dexter, P. D. (2015). The influence of engagement upon success and persistence of online undergraduates (Publication No. 3723157) [Doctoral dissertation, University of Southern Maine]. ProQuest Dissertations Publishing. https://search.proquest.com/docview/1728895868

Grau-Valldosera, J., Minguillón, J., \& Blasco-Moreno, A. (2018). Returning after taking a break in online distance higher education: From intention to effective re-enrollment. Interactive Learning Environments, 27(3), 307-323. https://doi.org/10.1080/10494820.2018.1470986 
Han, X., Wang, Y., \& Jiang, L. (2019). Towards a framework for institution-wide quantitative assessment of teacher's online participation in blended learning implementation. The Internet and Higher Education, 42, 1-12. https://doi.org/10.1016/j.iheduc.2019.03.003

Hart, C. (2012). Factors associated with student persistence in an online program of study: A review of the literature. Journal of Interactive Online Learning, 11(1), 19-42.

http://www.ncolr.org/jiol/issues/pdf/11.1.2.pdf

Henry, M. (2018). The online student experience: An exploration of first-year university students' expectations, experiences and outcomes of online education [Doctoral dissertation, Edith Cowan University]. Research Online Institutional Repository. https://ro.ecu.edu.au/theses/2059

Houlden, S., \& Veletsianos, G. (2019). A posthumanist critique of flexible online learning and its "anytime anyplace" claims. British Journal of Educational Technology, 5o(3), 1005-1018. https://doi.org/10.1111/bjet.12779

Hyllegard, D., Deng, H., \& Hunter, C. (2008). Why do students leave online courses? Attrition in community college distance learning courses. International Journal of Instructional Media, $35(4), 429-434$. https://link.gale.com/apps/doc/A273359032/AONE?u=anon d10fo403\&sid=googleScholar \&xid $=\operatorname{cc} 2 \mathrm{cfc} 27$

Kahu, E., Stephens, C., Zepke, N., \& Leach, L. (2014). Space and time to engage: Mature-aged distance students learn to fit study into their lives. International Journal of Lifelong Education, 33(4), 523-540. https://doi.org/10.1080/02601370.2014.884177

Kara, M., Erdoğdu, F., Kokoç, M., \& Cagiltay, K. (2019). Challenges faced by adult learners in online distance education: A literature review. Open Praxis, 11(1), 5-22. https://doi.org/10.5944/openpraxis.11.1.929

Korstange, R., Hall, J., Holcomb, J., \& Jackson, J. (2020). The online first-year experience: Defining and illustrating a new reality. Adult Learning, 31(3), 95-108. https://doi.org/10.1177/1045159519892680

Lee, Y., \& Choi, J. (2011). A review of online course dropout research: Implications for practice and future research. Educational Technology Research and Development, 59(5), 593-618. https://doi.org/10.1007/s11423-010-9177-y

McNaught, K. (2013). Flexible pedagogy, flexible practice: Notes from the trenches of distance education. Higher Education Research \& Development, 32(5), 867-869.

https://doi.org/10.1080/07294360.2012.756849

Michinov, N., Brunot, S., Le Bohec, O., Juhel, J., \& Delaval, M. (2011). Procrastination, participation, and performance in online learning environments. Computers \& Education, 56(1), 243-252. https://doi.org/10.1016/j.compedu.2010.07.025 
Moore, C., \& Greenland, S. (2017). Employment-driven online student attrition and the assessment policy divide: An Australian open-access higher education perspective. Journal of Open, Flexible and Distance Learning, 21(1), 52-62. https://files.eric.ed.gov/fulltext/EJ1148193.pdf

Mor, Y., Ferguson, R., \& Wasson, B. (2015). Editorial: Learning design, teacher inquiry into student learning and learning analytics: A call for action. British Journal of Educational Technology, 46(2), 221-229. https://doi.org/10.1111/bjet.12273

Mulliner, E., \& Tucker, M. (2017). Feedback on feedback practice: Perceptions of students and academics. Assessment \& Evaluation in Higher Education, 42(2), 266-288. https://doi.org/10.1080/02602938.2015.1103365

Naidu, S. (2017). How flexible is flexible learning, who is to decide and what are its implications? [Editorial]. Distance Education, 38(3), 269-272. https://doi.org/10.1080/01587919.2017.1371831

Naylor, D. \& Nyanjom, J. (2020). Educators' emotions involved in the transition to online teaching in higher education. Higher Education Research \& Development. Advance online publication. http://doi.org/10.1080/07294360.2020.1811645

Nguyen, Q., Rienties, B., Toetenel, L., Ferguson, F., \& Whitelock, D. (2017). Examining the designs of computer-based assessment and its impact on student engagement, satisfaction, and pass rates. Computers in Human Behavior, 76, 703-714.

https://doi.org/10.1016/j.chb.2017.03.028

Nikolova, I., \& Collis, B. (1998). Flexible learning and design of instruction. British Journal of Educational Technology, 29(1), 59-72. https://doi.org/10.1111/1467-8535.00046

Owen, M., Kavanagh, P., \& Dollard, M. (2017). An integrated model of work-study conflict and workstudy facilitation. Journal of Career Development, 45(5), 504-517. https://doi.org/10.1177/0894845317720071

Putney, L. G. (2010). Case study. In N. J. Salkind (Ed.), Encyclopedia of research design (Vol. 1, pp. 115-119). Sage Publications. https://doi.org/10.4135/9781412961288.n39

Ritchie, J., Lewis, J., Elam, G., Tennant, R., \& Rahim, N. (2014). Designing and selecting samples. In J. Ritchie, J. Lewis, C. M. Nicholls, \& R. Ormston (Eds.), Qualitative research practice: A guide for social science students and researchers (pp. 111-146). Sage Publications.

Sánchez-Gelabert, A., Valente, R., \& Duart, J. M. (2020). Profiles of online students and the impact of their university experience. International Review of Research in Open and Distributed Learning, 21(3), 230-249. https://doi.org/10.19173/irrodl.v21i3.4784

Sangrà, A. (2002). A new learning model for the information and knowledge society: The case of the Universitat Oberta de Catalunya (UOC), Spain. International Review of Research in Open and Distributed Learning, 2(2), 1-19. https://doi.org/10.19173/irrodl.v2i2.55

Schreier, M. (2016). Qualitative content analysis in practice. Sage Publications. 
Simpson, O. (2003). Student retention in online, open and distance learning. Routledge. https://www.routledge.co.uk/Student-Retention-in-Online-Open-and-DistanceLearning/Simpson/p/book/9780749439996

Simpson, O. (2013). Student retention in distance education: Are we failing our students? Open Learning, 28(2), 105-119. http://doi.org/10.1080/02680513.2013.847363.

Soffer, T., Kahan, T., \& Nachmias, R. (2019). Patterns of students' utilization of flexibility in online academic courses and their relation to course achievement. International Review of Research in Open and Distributed Learning, 2O(3). https://doi.org/10.19173/irrodl.v20i4.3949

Stone, C., \& O'Shea, S. (2019). Older, online and first: Recommendations for retention and success. Australasian Journal of Educational Technology, 35(1), 57-69. https://doi.org/10.14742/ajet.3913

Trotter, E., \& Roberts, C. A. (2006). Enhancing the early student experience. Higher Education Research \& Development, 25(4), 371-386. https://doi.org/10.1080/07294360600947368

Veletsianos, G., \& Houlden, S. (2019). An analysis of flexible learning and flexibility over the last 40 years of Distance Education. Distance Education, 4O(4), 454-468. https://doi.org/10.1080/01587919.2019.1681893

Veletsianos, G., Kimmons, R., Larsen, R., \& Rogers, J. (2021). Temporal flexibility, gender, and online learning completion. Distance Education, 42(1), 22-36. http://doi.org/10.1080/01587919.2020.1869523

Weimer, M. (2013). Learner-centered teaching: Five key changes to practice (2nd ed.). Jossey-Bass. https://www.wiley.com/enus/Learner+Centered+Teaching\%3A+Five+Key+Changes+to+Practice\%2C+2nd+Edition-p9781118119280

Willging, P. A., \& Johnson, S. D. (2009). Factors that influence students' decision to dropout of online courses. Journal of Asynchronous Learning Networks, 13(3), 115-127. https://files.eric.ed.gov/fulltext/EJ862360.pdf

Woodley, A., \& Simpson, O. (2014). Student dropout: The elephant in the room. In O. Zawacki-Richter \& T. Anderson (Eds.), Online distance education: Towards a research agenda (pp. 459-485). Athabasca University Press. https://doi.org/10.15215/aupress/9781927356623.01

Xavier, M., \& Meneses, J. (2020). Dropout in online higher education: A scoping review from 2014 to 2018. eLearn Center, Universitat Oberta de Catalunya. https://doi.org/10.7238/uoc.dropout.factors.2020

Yin, R. K. (2002). Case study research: Design and methods (3rd ed.). Sage Publications.

Young, S. (2006). Student views of effective online teaching in higher education. The American Journal of Distance Education, 20(2), 65-77. https://doi.org/10.1207/s15389286ajde2002 2 
The Tensions Between Student Dropout and Flexibility in Learning Design: The Voices of Professors in Open Online Higher Education Xavier and Meneses

\section{Athabasca \\ University}

cc) (†) 